\title{
Prevalence and Antimicrobial Resistance in Salmonella and Shigella Species Isolated from Outpatients, Jimma University Specialized Hospital, Southwest Ethiopia
}

\author{
Tesfahun Lamboro, Tsige Ketema, and Ketema Bacha \\ Department of Biology, College of Natural Sciences, Jimma University, P.O. Box 378, 1000 Jimma, Ethiopia \\ Correspondence should be addressed to Tsige Ketema; tsigeketema@gmail.com
}

Received 8 June 2016; Accepted 21 July 2016

Academic Editor: Jordi Vila

Copyright ( $\odot 2016$ Tesfahun Lamboro et al. This is an open access article distributed under the Creative Commons Attribution License, which permits unrestricted use, distribution, and reproduction in any medium, provided the original work is properly cited.

\begin{abstract}
This study was designed to investigate the prevalence of Salmonella and Shigella among outpatients in Jimma University Specialized Hospital, Southwest Ethiopia. Cross-sectional study was conducted involving a total of 176 outpatients. Stool specimens from both adult and pediatric outpatients were collected and analyzed for the presence of presumptive Salmonella and Shigella colonies followed by confirmation by biochemical tests. Pure cultures of Salmonella and Shigella species were further subjected to test for antibiotic resistance against the commonly used antibiotics. Furthermore, growth potential of the isolates in selected foods items was assessed following standard procedures. The result indicated that the prevalence of Salmonella and Shigella among outpatients in the study area was $19(10.8 \%)$ and $2(1.1 \%)$, respectively. In addition, Salmonella species were resistant to ampicillin (100\%) followed by tetracycline (47.4\%) and nalidixic acid (26.3\%) while Shigella species were highly resistant to ampicillin and tetracycline (100\%, each). Multidrug resistance towards maximum of four drugs was observed in both pathogens. The pathogens were observed growing to their infective dose within 24 hours. In conclusion, Salmonella and Shigella are still among microbes of public health importance in the study area. Thus, this calls for frequent monitory and evaluation of their prevalence and drug resistance patterns besides awareness development on water sanitation and hygienic food handling practices to the public at large.
\end{abstract}

\section{Introduction}

Infections associated with Salmonella and Shigella are among the major global public health problems. More than one billion cases of diarrhea occur worldwide due to nontyphoidal Salmonella every year leading to 3 million deaths [1]. Ninety-nine percent of the 200 million cases and more than 650,000 deaths per year due to infection with Shigella occur commonly in developing countries, primarily among children and young adults [2]. Salmonella and Shigella cause mild to severe forms of intestinal tract infection commonly associated with consumption of a variety of foods [3].

Salmonella is a leading cause of foodborne illness worldwide and can cause enterocolitis (salmonellosis), enteric fever (typhoid fever), and septicemia with general symptoms of fever, diarrhea, abdominal cramps, nausea, vomiting, chills, and prostration. Usually the disease lasts a few days and is self-limited although occasionally the infection can be more serious, with loss of fluid and electrolytes, and can be fatal, especially to the sick, infants, and the elderly $[1,2,4]$.

Shigella species are limited to the intestinal tract of humans and cause bacillary dysentery leading to watery or bloody diarrhea. Humans appear to be the only normal host reservoir for Shigella and they become infected by ingestion of contaminated food and water [5]. It is a highly infectious disease worldwide and its prevalence is the highest in tropical and subtropical regions of the world where living standard is very low and access to safe and adequate drinking water supply and proper excreta disposal system are often very limited or even absent $[2,5]$.

Ethiopia, as developing and tropical country, is frequently subjected to salmonellosis and shigellosis $[6,7]$. There are several studies on prevalence of Salmonella or Shigella in Ethiopia, but they are restricted to health facilities in some age groups: mainly pediatric or adults [8-11]. To date, however, there was no report made on the prevalence of these 
pathogens in both children and adult outpatients. Thus, this study was designed to determine the prevalence of Salmonella and Shigella in representative outpatients in Jimma University Specialized Hospital (JUSH) and to evaluate drug resistance patterns among the isolates.

\section{Materials and Methods}

2.1. Description of the Study Area. The study was conducted in Jimma town, located $353 \mathrm{~km}$ southwest of Addis Ababa, the capital city of Ethiopia. The town is geographically located at $7^{\circ} 41^{\prime} \mathrm{N}$ latitude, $36^{\circ} 50^{\prime} \mathrm{E}$ longitude, and an average altitude of 1, 780 meters above sea level. Jimma town is generally characterized by warm weather with mean annual maximum and minimum temperature of $30^{\circ} \mathrm{C}$ and $14^{\circ} \mathrm{C}$, respectively. The annual rainfall ranges between 1138 and 1690 millimeters [12]. Annually, Jimma University Specialized Hospital provides services for about 9000 inpatients and 80,000 outpatients, including clients of diverse socioeconomic and ethnic backgrounds, and bed capacity of 450 and a total of more than 550 staff members (https://www.ju.edu.et/jimma-universityspecialized-hospital-jush).

2.2. Study Design and Population. Cross-sectional study design was employed involving outpatients of Jimma University Specialized Hospital. Diarrheal adult and pediatric outpatients who fulfilled the inclusion criteria (any outpatients visiting the hospital during the study period and had diarrhea) were enrolled in the study. Those outpatients who had taken antibiotic a week prior to data collection time were excluded from the study. Accordingly, a total of 176 outpatients who fulfilled the inclusion criteria were enrolled in the study.

2.3. Sample Collection and Microbial Analysis. One-gram stool sample was collected from each patient using sterile screw capped tubes containing transport media $[9 \mathrm{~mL}$ buffered peptone water (Oxoid, UK)] and transported to Jimma University, Research and Postgraduate Laboratory for microbial analysis. After $24 \mathrm{hr}$ incubation at $37^{\circ} \mathrm{C}, 1 \mathrm{~mL}$ of the sample was transferred into $10 \mathrm{~mL}$ selenite $\mathrm{F}$ broth (Oxoid, $\mathrm{UK}$ ) and incubated. A loopful of culture was transferred onto xylose-lysine-deoxycholate agar (XLD) (Oxoid, UK) and incubated. The typical colonies were then further characterized based on colony morphology (Shigella appears as pink to red colonies on XLD, while Salmonella appears as red with black center). The cell morphology of pure culture was assessed by Gram staining. The morphological study includes cell shape, cell arrangement, presence or absence of endospore, and motility. Results of the isolates Gram reaction test were further confirmed with the rapid $\mathrm{KOH}$ method [13]. The isolates capability of catalase production, hence formation of bubbles, was checked using a $3 \% \mathrm{H}_{2} \mathrm{O}_{2}$ solution.

For identification of Shigella and Salmonella spp., all suspected colonies were inoculated into appropriate biochemical media including Triple Sugar Iron Agar (TSIA), Lysine Iron Agar (LIA), Urea Agar (UA), Simmon's Citrate Agar (SCA), and Sulfide Indole Motility (SIM) medium.

2.4. Antimicrobial Sensitivity Test. Antimicrobial susceptibility of 19 Salmonella spp. and 2 Shigella spp. was carried out by disc diffusion method using Mueller-Hinton agar and nine commonly used commercial antibiotics. The standard antibiotic discs (and their potency) used in the current study included ampicillin $\left(10 \mu \mathrm{gmL}^{-1}\right)$, nalidixic acid $\left(30 \mu \mathrm{gmL}^{-1}\right)$, amikacin $\left(30 \mu \mathrm{gmL}^{-1}\right)$, tetracycline $\left(30 \mu \mathrm{gmL}^{-1}\right)$, chloramphenicol $\left(30 \mu \mathrm{gmL}^{-1}\right)$, norfloxacin $\left(10 \mu \mathrm{gmL}^{-1}\right)$, gentamycin $\left(10 \mu \mathrm{gmL}^{-1}\right)$, ciprofloxacin $\left(5 \mu \mathrm{gmL}^{-1}\right)$, and cotrimoxazole $\left(25 \mu \mathrm{gmL}^{-1}\right)$. A reference strain of E. Coli ATCC 25922 was used as quality control.

A standardized suspension of the bacterial isolate was prepared and turbidity of the inoculum was matched with $0.5 \mathrm{McF}$ arland turbidity standard [14]. When bacterial culture containing the isolates matched the standard which was kept dark at room temperature, the culture was swabbed by cotton swab onto the Muller-Hinton Agar (Oxoid) and allowed to dry. Thereafter, the antibiotic discs were dispensed using sterile forceps on the medium and incubated at $37^{\circ} \mathrm{C}$ for $18 \mathrm{hr}$ and the zones of inhibition were measured. The results of the antimicrobial susceptibility were interpreted based on the guidance of National Committee for Clinical Laboratory Standards [15] and the isolates were classified as sensitive, intermediate, or resistant. Intermediates were considered as resistant for purpose of analysis.

2.5. Growth Potential of Salmonella and Shigella Isolated from Diarrheal Outpatients on Selected Food. Growth potential of Salmonella and Shigella isolated from diarrheal outpatients was assessed on two local food items (gruel, which is made from meat, and firfir, made from cereal) frequently utilized by the community. Briefly, $200 \mathrm{~g}$ of each food item was steamed at $100^{\circ} \mathrm{C}$, for a minute. Thereafter, $100 \mathrm{~g}$ of each food item was challenged with overnight culture of the isolates to give an inoculum level of $10^{2}-10^{3} \mathrm{cfu} / \mathrm{g}$. The challenged foods were left at ambient temperature for 24 hours. To investigate the initial inoculum level, inoculated foods (10 g each) were homogenised separately in $90 \mathrm{~mL}$ of buffered peptone water; and $0.1 \mathrm{~mL}$ of appropriate dilutions was spread-plated on XLD agar to count Salmonella and Shigella. Ten-gram portions of the food samples were further sampled aseptically at 6-hour intervals from 0 to 24 hours for microbial enumeration.

2.5.1. Statistical Analysis. Data was analyzed using SPSS software version 16 . All values were expressed as mean \pm standard deviation and the mean values of counts of Salmonella and Shigella in the two food samples during challenge study were compared using one-way ANOVA. The significance of differences was considered at 95\% confidence interval $(p<0.05)$.

2.6. Ethical Consideration. The study was ethically approved by Ethical Review Board of College of Natural Sciences. Written consent/assent for children $<18$ years old was obtained from guardians of the study participants prior to sample collection.

\section{Results}

3.1. Sociodemographic Characteristics of the Study Participants. A total of 176 diarrheal patients attending Outpatients 
TABLE 1: Sociodemographic characteristics of the study participants (outpatients), Jimma University Specialized Hospital, 2014.

\begin{tabular}{|c|c|c|c|}
\hline Characteristics & Category & Number of respondents & Percent (\%) \\
\hline \multirow{5}{*}{ Age } & $<10$ & 54 & 30.7 \\
\hline & $10-19$ & 39 & 22.2 \\
\hline & $20-29$ & 34 & 19.3 \\
\hline & $30-39$ & 26 & 14.8 \\
\hline & $>39$ & 23 & 13.1 \\
\hline \multirow{5}{*}{ Education level } & Illiterate & 52 & 29.6 \\
\hline & Grades 1-4 & 18 & 10.2 \\
\hline & $5-8$ & 21 & 11.9 \\
\hline & $9-12$ & 27 & 15.3 \\
\hline & $>12$ & 58 & 33.0 \\
\hline \multirow{2}{*}{ Gender } & Male & 84 & 47.7 \\
\hline & Female & 92 & 52.3 \\
\hline \multirow{2}{*}{ Residence } & Urban & 112 & 63.6 \\
\hline & Rural & 64 & 36.4 \\
\hline \multirow{4}{*}{ Occupation } & Unemployed & 96 & 54.5 \\
\hline & Businessmen & 28 & 15.9 \\
\hline & Farmer & 26 & 14.8 \\
\hline & Civil servant & 26 & 14.8 \\
\hline
\end{tabular}

Department of Jimma University Specialized Hospital were involved in the study with $100 \%$ response rate. About 33 $(18.8 \%)$ of the outpatients were in the age category of $<4$ years (Table 1). The proportions of female outpatients $(52.3 \%)$ were higher than males $(47.7 \%)$ of which $63.6 \%$ were urban residents.

3.2. Prevalence of Salmonella and Shigella. A total of 19 $(10.8 \%)$ and $2(1.1 \%)$ outpatients among the 176 outpatients seeking medication at Jimma University Specialized Hospital were found positive for Salmonella and Shigella, respectively. The frequency of isolation of Salmonella was the highest among outpatients aged between 20 and 24 and 5 and 9 years with none detected among those aged above 40 years (Table 2). The only two Shigella isolates $(1.1 \%)$ were encountered among children $<4$ years old. With the available few positive samples, the detection rate of Salmonella was relatively higher among male outpatients (10, 5.7\%) with almost equal rate of detection in rural and urban residents (5.7\% and $5.1 \%$, resp.) although the very low prevalence of Shigella $(1.1 \%)$ was encountered among illiterate rural farmers families aged $<4$ years (Table 2 ).

3.2.1. Antimicrobial Susceptibility Pattern of Salmonella and Shigella spp. All the 19 isolates of Salmonella spp. were susceptible to ciprofloxacin and norfloxacin (100\% each) followed by gentamycin (94.7\%), chloramphenicol (94.7\%), and amikacin (89.5\%) (Table 3). However, the highest frequency of resistance was observed for ampicillin (100\%) followed by tetracycline (47.4\%) and nalidixic acid (26.3\%) (Table 3). One isolate of Salmonella and Shigella species was found resistant to three similar antibiotics including chloramphenicol, gentamicin, and cotrimoxazole. Regarding Shigella spp., the two isolates were susceptible (100\%) to ciprofloxacin, norfloxacin, and gentamycin although resistance was observed for ampicillin and tetracycline (Table 3 ).

In line with the literary definition of multidrug resistance (MDR), resistant to more than one antimicrobial agent, the MDR profile of Salmonella spp. indicated that $42.1 \%$ of the isolates were resistant to two antibiotics followed by three $(26.3 \%)$ and four (21.0\%) antibiotics (Table 4). The maximum number of antibiotics resisted by Salmonella spp. was four although the highest MDR (42.1\%) was observed for combinations of two antibiotics: TE/AMP (resistance to tetracycline and ampicillin). Over all, resistance to two antibiotics dominated the resistance profile of Salmonella spp. The two Shigella isolates were resistant to four antibiotics of different patterns (TET/AMP/NAL/SXT and C/TET/AMP/AMK) (Table 4) (the codes are abbreviated below Table 4). Even with the current proposed definition of MDR, acquiring nonsusceptibility to at least one agent in three or more antimicrobial categories, Salmonella isolates displayed MDR as they were nonsensitive to many antibiotics that fall within more than five antimicrobial categories including Aminoglycoside (gentamicin), Fluoroquinolones (ciprofloxacin), Penicillins (ampicillin), Phenicols (chloramphenicol), and Tetracyclines (tetracycline) (Tables 3 and 4).

3.3. Growth Potential of Salmonella and Shigella. Growth potential of Salmonella species was analyzed in gruel and firfir (meat and cereal based traditional foods, resp.) over a period of $24 \mathrm{hr}$. During the first $6 \mathrm{hr}$, nearly similar growth was observed in both food items (Figure 1(a)). Thereafter, the growth rate was increased by $3 \log \mathrm{cfu} / \mathrm{g}$ in gruel (3.6-6.6 $\log \mathrm{cfu} / \mathrm{g})$ with relatively slow growth rate $(3.8-4.2 \log \mathrm{cfu} / \mathrm{g})$ in firfir until $12 \mathrm{hr}$. Finally, the count of Salmonella was as high as $7.2 \log \mathrm{cfu} / \mathrm{g}$ and $6.2 \log \mathrm{cfu} / \mathrm{g}$ in gruel and firfir, respectively, at the end of $24 \mathrm{hr}$ storage.

Similarly, the growth potential of Shigella spp. was assessed in the same food items (gruel and firfir) as indicated for Salmonella. The growth rate was higher in the gruel sample (2.51-3.8 log cfu/g) than in firfir sample (2.5-3.5 log cfu/g) during the first $6 \mathrm{hr}$ (Figure 1(b)). The growth rate increased by $1.5 \log \mathrm{cfu} / \mathrm{g}(3.5-5.14 \log \mathrm{cfu} / \mathrm{g})$ in firfir within $12 \mathrm{hr}$ and $3 \log \mathrm{cfu} / \mathrm{g}(3.8-6.9 \log \mathrm{cfu} / \mathrm{g})$ in gruel within $18 \mathrm{hr}$. Maximum growth as revealed with counts of $7.5 \log \mathrm{cfu} / \mathrm{g}$ (gruel) and $7.3 \mathrm{log} \mathrm{cfu} / \mathrm{g}$ (firfir) was observed within $24 \mathrm{hr}$ (Figure 1(b)).

$\mathrm{pH}$ values of the challenged food samples varied over the period of $24 \mathrm{hr}$ of storage. At the beginning $(0 \mathrm{hr})$, the $\mathrm{pH}$ value of gruel (6.32) was greater than that of firfir (5.14). Thereafter, the $\mathrm{pH}$ value of gruel was reduced from 5.66 to 5.00 between 6 and $12 \mathrm{hr}$ whereas that of firfir increased from 5.14 to 5.22 . Finally, it slightly rose up and reached 5.1 for gruel and 5.28 for firfir (Figure 2(a)). Likewise, in Shigella challenged foods, at $0 \mathrm{hr}$ of inoculation, the $\mathrm{pH}$ of gruel (6.32) was greater than the $\mathrm{pH}$ of firfir (5.14). Gradually, a slight $\mathrm{pH}$ reduction was observed in gruel up to $24 \mathrm{hr}$ while the same was observed for firfir with only minor fluctuation (5.23 to 5.22 ) between 6 and $12 \mathrm{hr}$ and it slightly increased and reached 5.28 at the end of $24 \mathrm{hr}$ (Figure 2(b)). 
TABle 2: Prevalence of Salmonella and Shigella against sociodemographic characteristics of the study participants, Jimma University Specialized Hospital, 2014.

\begin{tabular}{|c|c|c|c|c|}
\hline Characteristics & Alternative & Frequency number (\%) & Salmonella positive number (\%) & Shigella positive number (\%) \\
\hline \multirow{2}{*}{ Gender } & Male & $84(47.7)$ & $10(52.63)$ & $1(50)$ \\
\hline & Female & $92(52.3)$ & $9(47.37)$ & $1(50)$ \\
\hline \multirow{2}{*}{ Residence } & Urban & $112(63.6)$ & $9(47.37)$ & $0(0.0)$ \\
\hline & Rural & $64(36.4)$ & $10(52.63)$ & $2(100)$ \\
\hline \multirow{5}{*}{ Age } & $<10$ & $54(30.68)$ & $6(31.58)$ & $2(100)$ \\
\hline & $11-19$ & $39(22.15)$ & $3(15.79)$ & $0(0)$ \\
\hline & $20-29$ & $34(19.32)$ & $7(36.84)$ & $0(0)$ \\
\hline & $30-39$ & $26(14.77)$ & $3(15.79)$ & $0(0)$ \\
\hline & $>39$ & $23(13.07)$ & $0(0)$ & $0(0)$ \\
\hline \multirow{5}{*}{ Educational } & Illiterate & $52(29.6)$ & $7(36.84)$ & $2(100)$ \\
\hline & $1-4$ & $18(10.2)$ & $2(10.52)$ & $0(0.0)$ \\
\hline & $5-8$ & $21(11.9)$ & $5(26.31)$ & $0(0.0)$ \\
\hline & $9-12$ & $27(15.3)$ & $1(5.26)$ & $0(0.0)$ \\
\hline & $>12$ & $58(33.0)$ & $4(21.05)$ & $0(0.0)$ \\
\hline \multirow{4}{*}{ Occupation } & Unemployed & $96(54.5)$ & $14(73.68)$ & $0(0.0)$ \\
\hline & Businessmen & $28(15.9)$ & $3(15.79)$ & $0(0.0)$ \\
\hline & Farmer & $26(14.8)$ & $2(10.52)$ & $2(100)$ \\
\hline & Civil servant & $26(14.8)$ & $0(0.0)$ & $0(0.0)$ \\
\hline
\end{tabular}

TABle 3: Antimicrobial susceptibility pattern of Salmonella and Shigella spp. isolated from diarrheal outpatients in Jimma University Specialized Hospital, Jan-Mar, 2014.

\begin{tabular}{|c|c|c|c|c|c|c|c|}
\hline \multirow{2}{*}{$\begin{array}{l}\text { Antimicrobial } \\
\text { agents }\end{array}$} & \multirow{2}{*}{$\begin{array}{l}\text { Disc potency } \\
\left(\mu \mathrm{gmL}^{-1}\right)\end{array}$} & \multicolumn{3}{|c|}{ Salmonella spp. } & \multicolumn{3}{|c|}{ Shigella spp. } \\
\hline & & $\begin{array}{c}\text { Resistant } \\
\text { number (\%) }\end{array}$ & $\begin{array}{c}\text { Intermediate } \\
\text { number (\%) }\end{array}$ & $\begin{array}{c}\text { Sensitive } \\
\text { number (\%) }\end{array}$ & $\begin{array}{c}\text { Resistant } \\
\text { number (\%) }\end{array}$ & $\begin{array}{c}\text { Intermediate } \\
\text { number (\%) }\end{array}$ & $\begin{array}{c}\text { Sensitive } \\
\text { number (\%) }\end{array}$ \\
\hline Amikacin & 30 & - & $2(10.5)$ & $17(89.5)$ & - & $1(50)$ & $1(50)$ \\
\hline Ciprofloxacin & 5 & - & - & $19(100)$ & - & - & $2(100)$ \\
\hline Chloramphenicol & 30 & $1(5.2)$ & - & $18(94.7)$ & - & $1(50)$ & $1(50)$ \\
\hline Gentamycin & 10 & $1(5.2)$ & - & $18(94.7)$ & - & - & $2(100)$ \\
\hline Cotrimoxazole & 25 & $1(5.2)$ & $5(26.3)$ & $13(68.4)$ & $1(50)$ & - & $1(50)$ \\
\hline Norfloxacin & 30 & - & - & $19(100)$ & - & - & $2(100)$ \\
\hline Nalidixic acid & 30 & $5(26.3)$ & $4(21.05)$ & $10(52.6)$ & $1(50)$ & - & $1(50)$ \\
\hline Ampicillin & 10 & $19(100)$ & - & - & $2(100)$ & - & - \\
\hline Tetracycline & 30 & $9(47.4)$ & $3(15.7)$ & $7(36.8)$ & $2(100)$ & - & - \\
\hline
\end{tabular}

\section{Discussion}

There are reports on widespread occurrence and distribution of Salmonella and Shigella in Ethiopia [8, 9, 11, 16, 17]. Recently, the number of Salmonella and Shigella related outbreaks in humans has still increased considerably in the same country [11]. Accurate estimates of the burden of diarrheal diseases caused by Salmonella species and other foodborne pathogens are needed to effectively set public health goals and allocate resources to reduce disease burden [18]. Accordingly, our finding indicated that, of the total 176 diarrheal outpatients, $10.8 \%$ were positive for Salmonella and $1.1 \%$ were positive for Shigella. The prevalence rate of Salmonella in this study is in agreement with that in the earlier studies reported as 10.7\% [17], 11.5\% [9], 13.6\% [19], and 10.5\% [11] but lower than that in a study reported as $15.4 \%$ [16] and higher than the 7.2\% prevalence reported by Awole et al. [8].

In this study, the prevalence rate of Shigella was much lower than what was reported by Ashenafi and Gedebou [20] (9\%) and Asrat et al. [21] (11.7\%) from Tikur Anbessa, Ethio-Swedish Children's Hospital, and a report by Reda et al. [9] (6.7\%) from Harar, Ethiopia. The low isolation rate of Shigella in this study is comparable with the very recent report $(2.3 \%)$ made from among diarrheal children in Jimma Health Center [10]. The low prevalence of the target pathogens, especially Shigella, in the current study could be attributed to improved awareness of the community about personal and environmental hygiene from the continuous 
TABLE 4: MDR of Salmonella spp. and Shigella spp. isolated from diarrheal outpatients in Jimma University Specialized Hospital, Jan-Mar, 2014.

\begin{tabular}{|c|c|c|c|c|c|}
\hline \multirow{2}{*}{$\begin{array}{l}\text { Number of } \\
\text { antimicrobial } \\
\text { resistance values }\end{array}$} & \multicolumn{3}{|c|}{ Salmonella spp. } & \multicolumn{2}{|c|}{ Shigella spp. } \\
\hline & $\begin{array}{l}\text { Antimicrobial resistance } \\
\text { patterns }\end{array}$ & $\begin{array}{c}\text { Number of isolates } \\
(\%)\end{array}$ & $\begin{array}{c}\text { Total } \\
(\%)\end{array}$ & $\begin{array}{l}\text { Antimicrobial } \\
\text { resistance patterns }\end{array}$ & $\begin{array}{l}\text { Number of } \\
\text { isolates }\end{array}$ \\
\hline \multirow{3}{*}{ Two } & TET/AMP & $5(26.3)$ & \multirow{3}{*}{$8(42.1)$} & - & \\
\hline & SXT/AMP & $1(5.2)$ & & - & \\
\hline & NAL/AMP & $2(10.52)$ & & - & \\
\hline \multirow{3}{*}{ Three } & TET/NAL/AMP & $2(10.52)$ & \multirow{3}{*}{$5(26.3)$} & - & \\
\hline & SXT/AMP/TET & $2(10.52)$ & & - & \\
\hline & NAL/SXT/AMP & $1(5.2)$ & & - & \\
\hline \multirow{4}{*}{ Four } & NAL/AMP/TET/SXT & $1(5.2)$ & \multirow{4}{*}{$4(21.0)$} & TET/AMP/NAL/SXT & 1 \\
\hline & NAL/TET/AMP/C & $1(5.2)$ & & C/TET/AMP/AMK & 1 \\
\hline & AMP/SXT/CN/NAL & $1(5.2)$ & & & \\
\hline & AMK/AMP/NAL/TET & $1(5.2)$ & & & \\
\hline
\end{tabular}

TET: tetracycline, AMP: ampicillin, SXT: cotrimoxazole, NAL: nalidixic acid, C: chloramphenicol, CN: gentamycin, AMK: amikacin, CIP: ciprofloxacin, and NOR: norfloxacin.

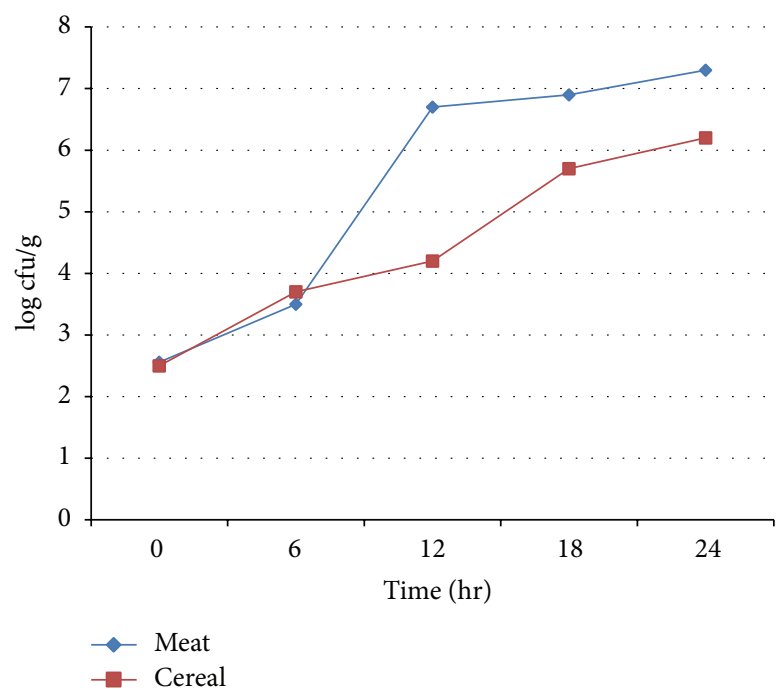

(a)

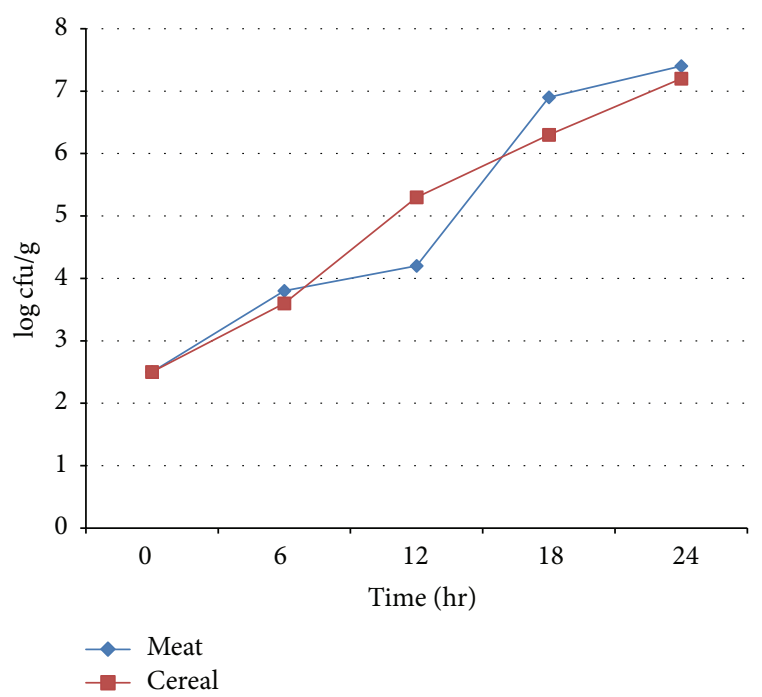

(b)

Figure 1: Growth potential of species of Salmonella (a) and Shigella (b) isolated from diarrheal outpatients on meat and cereal products (Jimma University Specialized Hospital, 2014).

interventions being made by different stakeholders including the Health Science students of Jimma University through the educational program called Community Based Education.

Several studies showed possible differences in the frequency of isolation of Salmonella and Shigella infection among different age groups [11,22]. Accordingly, the highest isolation rate of Salmonella was observed in the age group between 20 and 24 (26.3\%) and 5 and 9 (26.3\%) as supported by earlier reports made from Ethiopia by Mache [16] and Mengistu et al. [11]. To the contrary, Shigella species were encountered only in the age group below five. This is in agreement with reports from different parts of the world including Ethiopia [7,23]. Therefore, shigellosis occurs worldwide but is most common among pediatric age group in underdeveloped tropical countries including Ethiopia. Community based data on shigellosis are incomplete but most hospital data suggested that the case-fatality rate is the highest among children less than 5 years old particularly if there is malnutrition. In epidemic shigellosis, the rate is as high as $3.9 \%$ in children under the age of 1 and $19.3 \%$ for infants less than 4 months of age. The case fatality declines with increase in age [18, 23]. Understanding the prevalence rate among different age groups is important to target intervention and preventive measures based on their age group.

In relation to educational status and frequency of isolation, this study indicated that there was high isolation rate of Salmonella and Shigella among the illiterates, with $36.8 \%$ and $100 \%$ isolation rates, respectively. This result is comparable with earlier study made by Aziz et al. [24]. Education is vital to create awareness in the community with regard 


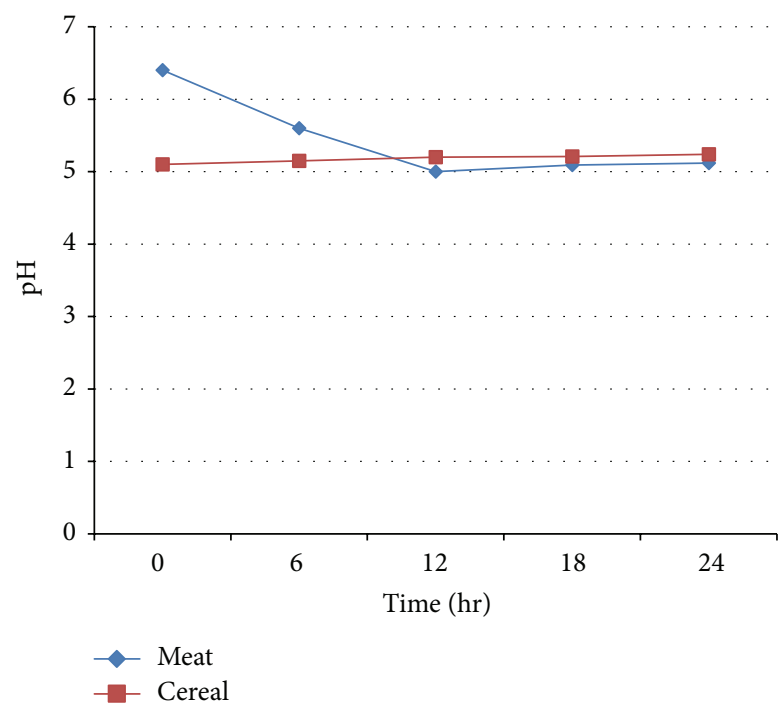

(a)

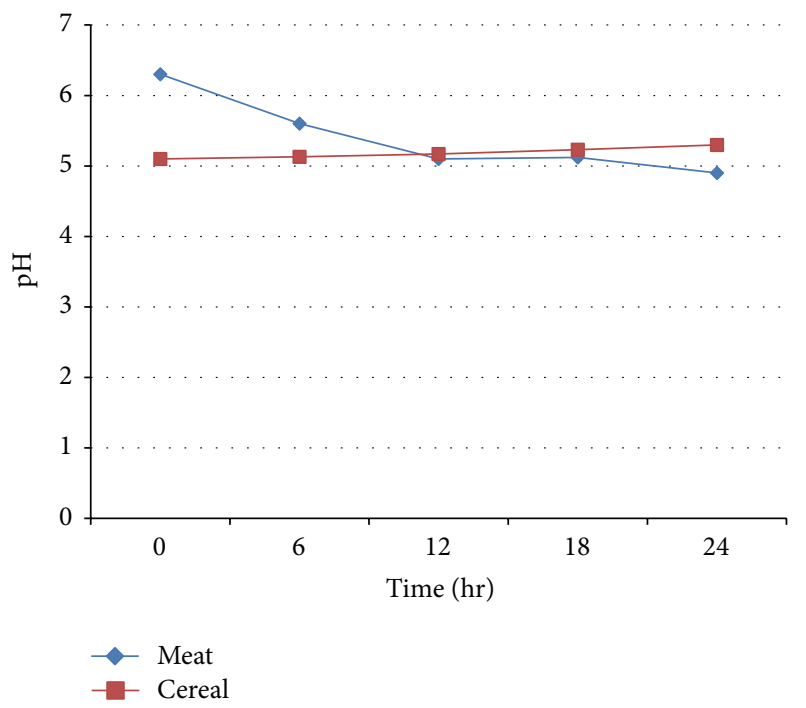

(b)

FIGURE 2: $\mathrm{pH}$ values of meat and cereal products challenged with species of Salmonella (a) and Shigella (b) isolated from diarrheal outpatients (Jimma University Specialized Hospital, 2014).

to the mechanism of management of infectious diarrhea and control of other factors that lead to this disease. Poor environmental sanitation, malnutrition, inadequate water supply, poverty, and limited education are the major factors implicated in the occurrence, spread, and severity of diarrheal disease [25].

Due to selective pressure created by the use of antimicrobials in food processing animals, the risk of antimicrobial resistance among food borne pathogens has increased [26]. Mobile elements such as plasmids and transposons facilitate the rapid spread of antibiotic resistant genes among bacteria [27]. In addition, high rates of antibiotic resistant bacteria may possibly result from inappropriate or uncontrolled use of antibiotics. Therefore, it is necessary to pay attention to hygienic food handling practice as well as avoiding uncontrolled use of antibiotics [28]. An increase in the antimicrobial resistance in Salmonella and Shigella makes the treatment of infection more challenging. Therefore, epidemiological information and monitoring system are necessary to control Salmonella and Shigella infection in public health sectors.

In agreement with studies conducted by Beyene and Tasew [10], Shigella isolates were susceptible to ciprofloxacin, gentamicin, and norfloxacin. The resistance of Shigella spp. towards ampicillin and tetracycline is in agreement with studies conducted by Roma et al. [29] who reported high rate of resistance of Shigella spp. to ampicillin (93\%), erythromycin (90\%), tetracycline (90\%), and cotrimoxazole (56\%). Asrat [21] also reported high rate of resistance of Shigella species to tetracycline (97.3\%) and ampicillin (78.7\%).

The high level of antibiotic susceptibility of Salmonella to ciprofloxacin and norfloxacin is in agreement with earlier studies reported from Ethiopia $[10,11]$. The resistance of Salmonella towards ampicillin (100\%) and tetracycline (47.4\%) was in agreement with report made by Beyene and Tasew [10] where most of the Salmonella isolates were resistant to ampicillin. In the current study, multidrug resistance towards four drugs was observed in Salmonella and Shigella.

The challenge studies revealed that Salmonella species reached the infective dose ( $5 \log \mathrm{cfu} / \mathrm{g}$ ) within 12 and $18 \mathrm{hr}$ in gruel and firfir, respectively. The maximum count obtained was $7.2 \mathrm{log} \mathrm{cfu} / \mathrm{g}$ in gruel and $6.2 \mathrm{log} \mathrm{cfu} / \mathrm{g}$ in firfir. As compared to the previous study [30], the maximum count obtained in this study was relatively smaller. The reason for this difference can be the acidic nature of the food and the nature of the ingredients from which the food was prepared. For the cause of typhoid, an individual should have a minimum oral dose of $10^{5} \mathrm{~S}$. typhimurium whereas at least $10^{9}$ S. typhimurium cells are required to cause symptoms of toxic infection. It takes $12-24 \mathrm{hr}$ incubation after a person takes contaminated food containing sufficient number of Salmonella to manifest disease symptoms such as diarrhea, vomiting, and fever [31].

Likewise, Shigella species grow to the level of infective doses within 6 to $12 \mathrm{hr}$. The pathogen could initiate a successful infection at this cell number. The maximum growth observed in the current study was relatively lower as compared to studies reported by Ashenafi and Gedebou [20]. The reason for this discrepancy is the relatively acidic nature of gruel at the end of $24 \mathrm{hr}$. Even though the gruel is relatively acidic, Shigella manage to grow to the maximum of $>7 \log \mathrm{cfu} / \mathrm{g}$ within $24 \mathrm{hr}$ period. This is because the pathogen can manage to grow in low $\mathrm{pH}$ food items [32]. Since this food item is frequently utilized by babies, care should be taken when handling the food; extension of the food before use should also be avoided. The maximum growth of Shigella species in firfir was almost similar with a very minor increment in gruel. The growth of Shigella species in firfir was steadier than that in gruel. The pathogens reach their infective dose within 6 to $12 \mathrm{hr}$. This is in agreement with studies reported by Ashenafi and Gedebou [20]. 


\section{Conclusion}

Findings of the current study revealed higher prevalence $(10.8 \%, N=176)$ of Salmonella species, dominantly among outpatients aged less than five years. The prevalence of Shigella (1.1\%) was significant as compared to Salmonella. Furthermore, all Salmonella spp. were resistant to ampicillin although more than $90 \%$ of the isolates were susceptible to ciprofloxacin, norfloxacin, gentamycin, and chloramphenicol. Besides other factors, the potential health risks of the observed prevalences of Salmonella and Shigella were revealed by luxurious growth of both pathogens in the commonly used foods in the study area. This calls for designing of strategies for better awareness development among the community on hygienic food and water handling practices besides appropriate control measures. Thus, result of the present study will strengthen the knowledge in the field of epidemiology of Salmonella and Shigella to generate further trials which may help policy makers in planning interventions for the at risk population in the field of water sanitation and hygienic food handling practice. Furthermore, the observed drug resistance in Salmonella and Shigella can be used as an input by the health institutes for appropriate drug subscription.

$\begin{array}{ll}\text { Abbreviations } \\ \text { XLD: } & \text { Xylose lysine deoxycholate } \\ \text { KOH: } & \text { Potassium hydroxide } \\ \mathrm{H}_{2} \mathrm{O}_{2}: & \text { Hydrogen peroxide } \\ \text { TSIA: } & \text { Triple Sugar Iron Agar } \\ \text { LIA: } & \text { Lysine Iron Agar } \\ \text { UA: } & \text { Urea Agar } \\ \text { SCA: } & \text { Simmon's Citrate Agar } \\ \text { SIM: } & \text { Sulfide Indole Motility } \\ \text { ATCC: American type culture collection } \\ \text { TET: } & \text { Tetracycline } \\ \text { AMP: } & \text { Ampicillin } \\ \text { SXT: } & \text { Cotrimoxazole } \\ \text { NAL: } & \text { Nalidixic acid } \\ \text { C: } & \text { Chloramphenicol } \\ \text { CN: } & \text { Gentamycin } \\ \text { AMK: } & \text { Amikacin } \\ \text { CIP: } & \text { Ciprofloxacin } \\ \text { NOR: } & \text { Norflaxacin. }\end{array}$

\section{Competing Interests}

The authors declare that they have no competing interests.

\section{Acknowledgments}

The authors would like to thank Jimma University for financial and material support. Also they are grateful to all the study participants for their willingness and health professionals for their professional support.

\section{References}

[1] B. Coburn, G. A. Grassl, and B. B. Finlay, "Salmonella, the host and disease: a brief review," Immunology and Cell Biology, vol. 85, no. 2, pp. 112-118, 2007.
[2] D. L. Kasper, A. S. Fauci, D. L. Longo, E. Braunwald, S. L. Hauser, and J. L. Jameson, Harrison's Principles of Internal Medicine, McGraw-Hill, New York, NY, USA, 2005.

[3] L. J. Harris, J. N. Farber, L. R. Beuchat et al., "Outbreaks associated with fresh produce: incidence, growth, and survival of pathogens in fresh and fresh-cut produce," Comprehensive Reviews in Food Science and Food Safety, vol. 2, no. 1, pp. 78$141,2003$.

[4] S. Arslan and A. Eyi, "Occurrence and antimicrobial resistance profiles of Salmonella species in retail meat products," Journal of Food Protection, vol. 73, no. 9, pp. 1613-1617, 2010.

[5] D. R. Arora, Textbook of Microbiology, CBC Publisher and Distributer, New Delhi, India, 3rd edition, 2008.

[6] A. Sebhat, E. T. Erque, M. Andargachew, and A. Kassu, "A case of shigellosis with intractable septic shock and convulsion," Japan Journal of Infectious Disease, vol. 60, pp. 314-316, 2007.

[7] M. Tiruneh, "Serodiversity and antimicrobial resistance pattern of Shigella isolates at Gondar University Teaching Hospital, northwest Ethiopia," Japanese Journal of Infectious Diseases, vol. 62, no. 2, pp. 93-97, 2009.

[8] M. Awole, S. Gebre-Selassie, T. Kassa, and G. Kibru, "Isolation of potential bacterial pathogens from the stool of HIVinfected and HIV-non-infected patients and their antimicrobial susceptibility patterns in Jimma Hospital, Southwest Ethiopia," Ethiopian Medical Journal, vol. 40, pp. 353-364, 2002.

[9] A. A. Reda, B. Seyoum, J. Yimam, G. Andualem, S. Fiseha, and J.-M. Vandeweerd, "Antibiotic susceptibility patterns of Salmonella and Shigella isolates in Harar, Eastern Ethiopia," Journal of Infectious Diseases and Immunity, vol. 3, pp. 134-139, 2011.

[10] G. Beyene and H. Tasew, "Prevalence of intestinal parasite, Shigella and Salmonella species among diarrheal children in Jimma health center, Jimma southwest Ethiopia: a cross sectional study," Annals of Clinical Microbiology and Antimicrobials, vol. 13, pp. 1-7, 2014.

[11] G. Mengistu, G. Mulugeta, T. Lema, and A. Aseffa, "Prevalence and antimicrobial susceptibility patterns of Salmonella serovars and Shigella species," Journal of Microbial \& Biochemical Technology, vol. 32, pp. 1-7, 2014.

[12] A. Alemu, W. Tsegaye, L. Golassa, and G. Abebe, "Urban malaria and associated risk factors in Jimma town, south-west Ethiopia," Malaria Journal, vol. 10, pp. 173-200, 2011.

[13] T. Gregersen, "Rapid method for distinction of gram-negative from gram-positive bacteria," European Journal of Applied Microbiology and Biotechnology, vol. 5, no. 2, pp. 123-127, 1978.

[14] J. MacFaddin, Biochemical Tests for Identification of Medical Bacteria, Williams \& Wilkins, 1976.

[15] National Committee for Clinical and Laboratory Standards, Performance Standards for Antimicrobial Disk Susceptibility Tests, Approved Standard M2-A8, NCCLS, Wayne, Pa, USA, 8th edition, 2007.

[16] A. Mache, "Salmonella serogroup and their antibiotic resistance patterns isolated from diarrhoeal stools of pediatric outpatients in Jimma Hospital and Jimma Health Center, South West Ethiopia," Ethiopian Journal of Health Sciences, vol. 37, pp. 3745, 2002.

[17] B. Andualem and A. Geyid, "Antimicrobial responses of Yersinia enterocolitica isolates in comparison to other commonly encountered bacteria that causes diarrhoea," East African Medical Journal, vol. 82, no. 5, pp. 241-246, 2005. 
[18] R. B. Savadkoohi and M. Ahmadpour-Kacho, "Prevalence of Shigella species and their antimicrobial resistance patterns at Amirkola children's hospital, North of Iran," Iranian Journal of Pediatrics, vol. 17, no. 2, pp. 118-122, 2007.

[19] Z. Addis, N. Kebede, Z. Worku, H. Gezahegn, A. Yirsaw, and T. Kassa, "Prevalence and antimicrobial resistance of Salmonella isolated from lactating cows and in contact humans in dairy farms of Addis Ababa: a cross sectional study," BMC Infectious Diseases, vol. 11, article 222, 2011.

[20] M. Ashenafi and M. Gedebou, "Salmonella and Shigella in adult diarrhoea in Addis Ababa-prevalence and antibiograms," Transactions of the Royal Society of Tropical Medicine and Hygiene, vol. 79, no. 5, pp. 719-721, 1985.

[21] D. Asrat, A. Hathaway, and E. Ekwall, "Studies on enteric campylobacteriosis in Tikur Anbessa and Ethio-Swedish children's hospital, Addis Ababa, Ethiopia," Ethiopian Medical Journal, vol. 37, no. 2, pp. 71-84, 1999.

[22] A. S. Karim, S. Akhter, M. A. Rahman, and M. F. Nazir, "Risk factors of persistent diarrhea in children below five years of age," Indian Journal of Gastroenterology, vol. 20, no. 2, pp. 59-61, 2001.

[23] A. David, C. L. Sack, L. Corol, and S. Vorvit, "Antimicrobial resistance in shigellosis, Cholera and campylobacter," WHO/CDC/CSR/DRS, vol. 8, pp. 21-30, 2001.

[24] K. M. A. Aziz, B. A. Hoque, K. Z. Hasan et al., "Reduction in diarrhoeal diseases in children in rural Bangladesh by environmental and behavioural modifications," Transactions of the Royal Society of Tropical Medicine and Hygiene, vol. 84, no. 3, pp. 433-438, 1990.

[25] J. K. Nath, B. Sally, and J. Martin, "Handling and points of use treatment. A review commissioned by IFH," pp. 1-15, 2006, http://www.ifh-homehygiene.org.

[26] C.-H. Chiu, T.-L. Wu, L.-H. Su et al., "The emergence in Taiwan of fluoroquinolone resistance in Salmonella enterica serotype choleraesuis," The New England Journal of Medicine, vol. 346, no. 6, pp. 416-419, 2002.

[27] M. Sunde, "Prevalence and characterization of class 1 and class 2 integrons in Escherichia coli isolated from meat and meat products of Norwegian origin," Journal of Antimicrobial Chemotherapy, vol. 56, no. 6, pp. 1019-1024, 2005.

[28] T. T. H. Van, G. Moutafis, T. Istivan, L. T. Tran, and P. J. Coloe, "Detection of Salmonella spp. in retail raw food samples from vietnam and characterization of their antibiotic resistance," Applied and Environmental Microbiology, vol. 73, no. 21, pp. 6885-6890, 2007.

[29] B. Roma, S. Worku, S. T. Mariam, and N. Langeland, "Antimicrobial susceptibility pattern of Shigella isolates in Awassa," Ethiopian Journal of Health Development, vol. 14, article 154, 2000.

[30] D. Muleta and M. Ashenafi, "Salmonella, Shigella and growth potential of other food-borne pathogens in Ethiopian street vended foods," East African Medical Journal, vol. 78, no. 11, pp. 576-580, 2001.

[31] K. Todar, "Pathogenesis of Salmonella infection in human," 2012, http://textbookofbacteriology.net/salmonella_4.html.

[32] C. F. Bagamboula, M. Uyttendaele, and J. Debevere, "Acid tolerance of Shigella sonnei and Shigella flexneri," Journal of Applied Microbiology, vol. 93, no. 3, pp. 479-486, 2002. 


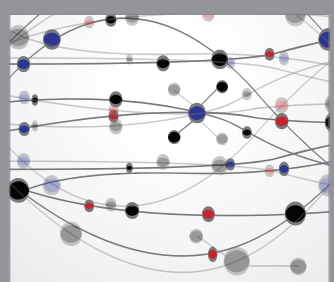

The Scientific World Journal
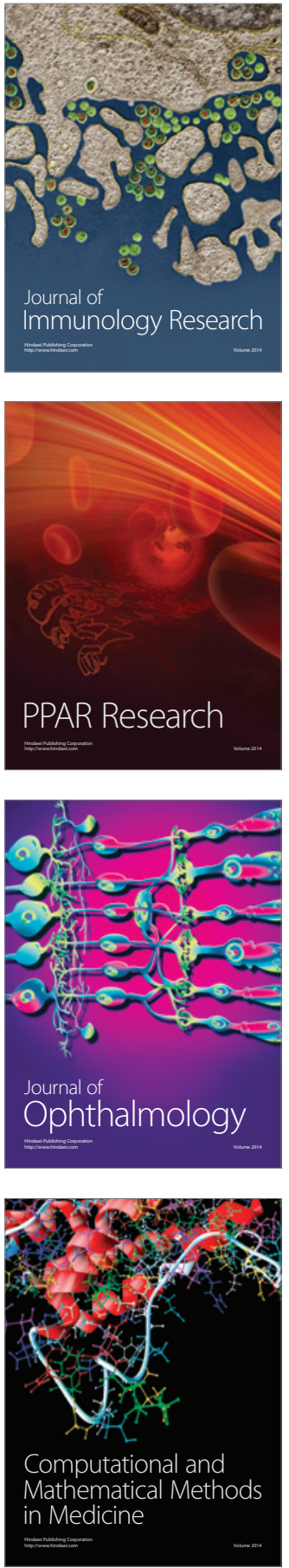

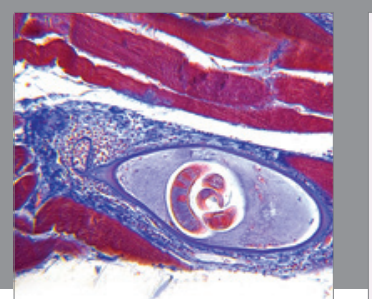

Gastroenterology Research and Practice

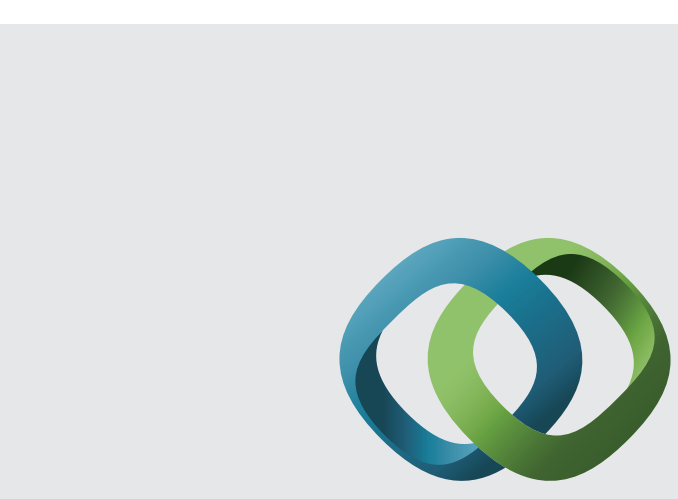

\section{Hindawi}

Submit your manuscripts at

http://www.hindawi.com
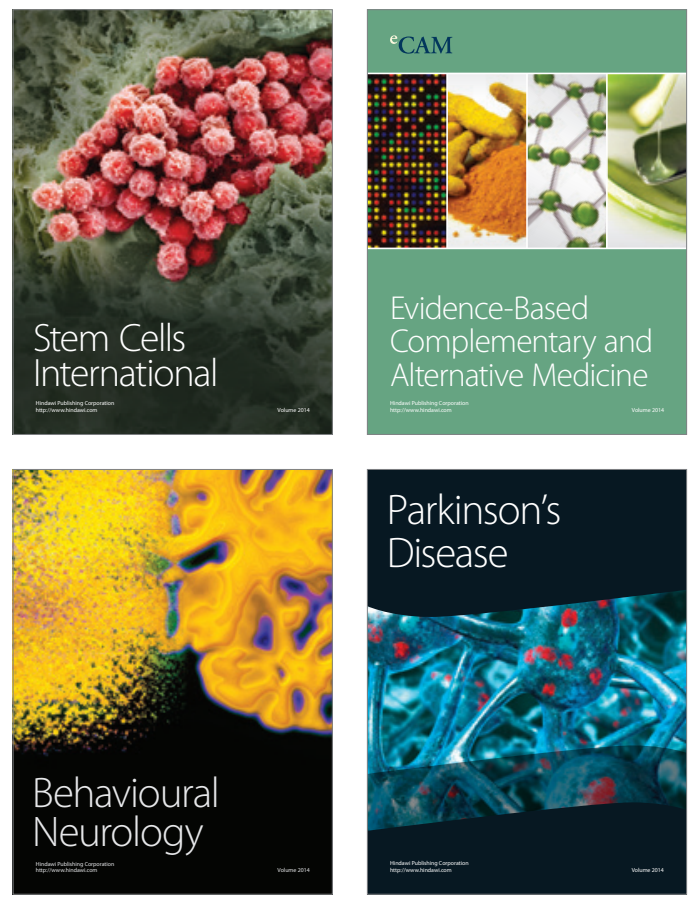
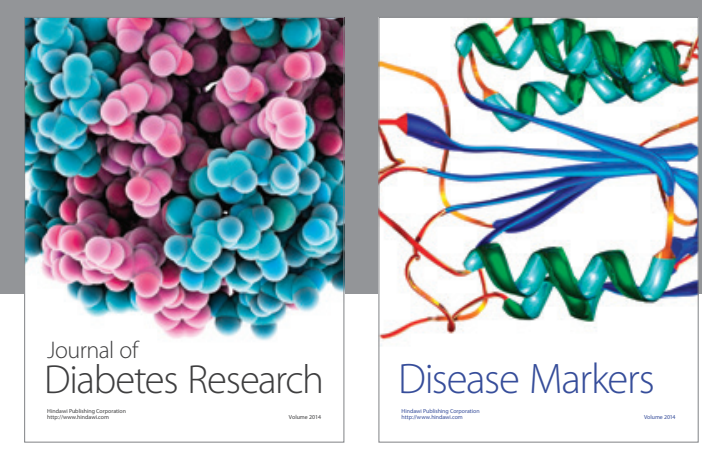

Disease Markers
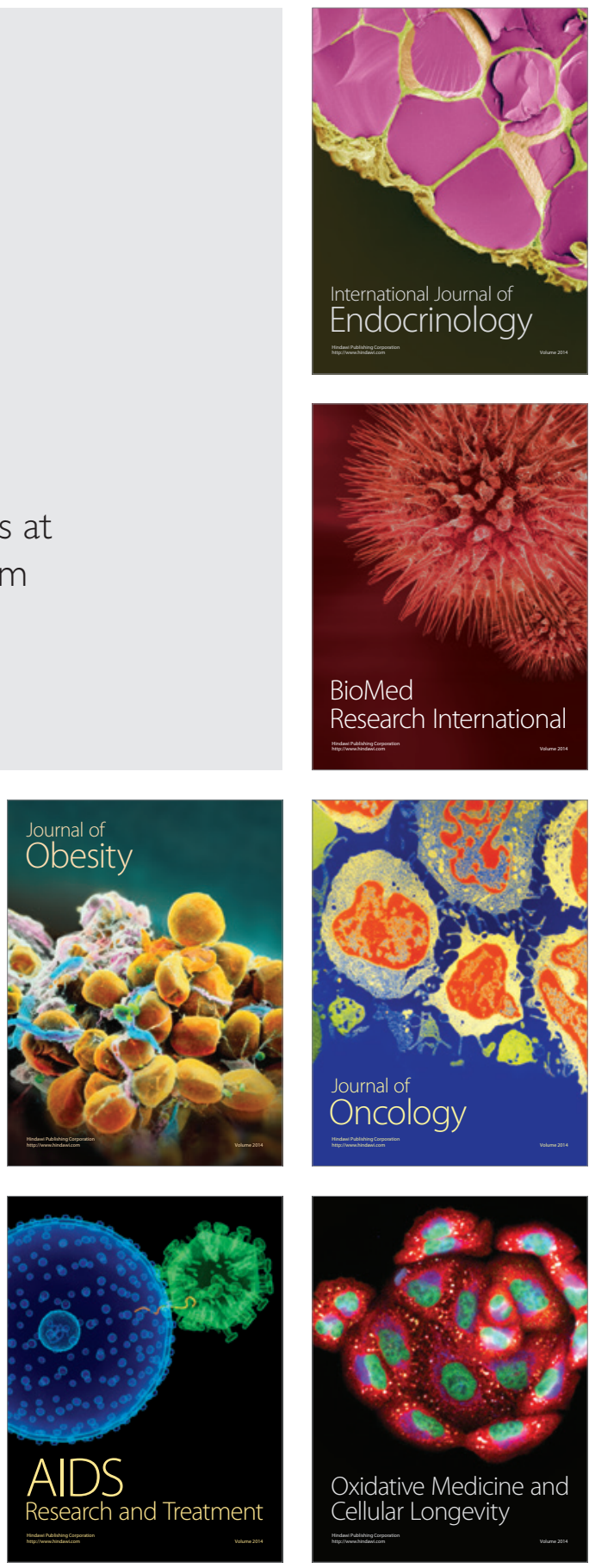